\title{
O PLURALISMO JURÍDICO FRENTE À CRISE DO MODELO MONISTA ESTATAL: APONTAMENTOS INTRODUTÓRIOS
}

\author{
Tuana Paula Lavall \\ Acadêmica do Curso de Direito da Universidade \\ Comunitária da Região de Chapecó (Unochapecó). \\ E-mail: tuanalavall@unochapeco.edu.br

\section{Maria Aparecida Lucca Caovilla} \\ Doutora em Direito pelo Programa de Pós-Graduação em \\ Direito da Universidade Federal de Santa Catarina (PPGD/ \\ UFSC), na área de concentração: Direito, Política e \\ Sociedade. Docente do curso de graduação em Direito e do \\ Programa de Pós-Graduação Stricto Sensu da Universidade \\ Comunitária da Região de Chapecó (Unochapecó). \\ Coordenadora do Grupo de Pesquisa Direitos Humanos e \\ Cidadania, certificado pelo CNPq. \\ E-mail: caovilla@unochapeco.edu.br
}

RESUMO: O paradigma jurídico tradicional, reconhecido por identificar o direito com a lei e situá-lo como produto exclusivo do Estado, atravessa, na contemporaneidade, uma crise profunda. Entre os fatores a evidenciar esse colapso, destacam-se o atraso com que as produções normativas acompanham as prementes modificações da sociedade e a incapacidade da justiça oficial em dar respostas aos conflitos submetidos ao seu crivo, dentro de um prazo razoável e com qualidade. O presente artigo se propõe a investigar como o pluralismo jurídico, segundo o enfoque teórico de Antonio Carlos Wolkmer, apresenta-se enquanto alternativa para a superação da referida crise enfrentada no campo do direito. Lançando mão do método dedutivo, por meio de pesquisa bibliográfica, transita-se pela questão do monismo jurídico, da crise de paradigmas que dele decorre, até se chegar à proposta do pluralismo. Nesse ponto, verifica-se que o pluralismo jurídico encampa apenas manifestações situadas à margem do direito positivo estatal, mas também pode erigir-se de práticas assentes dentro do próprio direito oficial.

PALAVRAS-CHAVE: Monismo Jurídico; Formalismo Jurídico; Dogmática Jurídica; Crise; Pluralismo Jurídico; Efetivação.

\section{Legal pluralism facing the crisis of the state monistic model: introductory points}

ABSTRACT: The traditional legal paradigm, acknowledged to identify the law with the legislation and situate it as an exclusive product of the state, crosses, in contemporary times, a deep crisis. Among the factors to highlight this collapse are the delay with which normative productions accompany the pressing changes of the society and the inability of the official justice to respond to the conflicts submitted to its sieve, within a reasonable time and with quality. This article proposes to investigate how legal pluralism, according to the theoretical approach of Antonio Carlos Wolkmer, presents itself as an alternative to overcome the referred crisis in the field of law. Using the deductive method, through bibliographical research, one moves through the question of juridical monism, of the crisis of paradigms that follow, until reaching the proposal of pluralism. At this point, it turns out that legal pluralism only includes manifestations 
situated outside the positive state law, or can be erected from practices based on official law itself.

KEYWORDS: Legal Monism; Legal Dogmatism; Legal Formalism; Crisis; Legal Pluralism; Effectiveness.

\section{INTRODUÇÃO}

O presente artigo tem como objetivo estudar o pluralismo jurídico, enquanto nova proposta paradigmática para o Direito - com assento teórico na formulação de Antonio Carlos Wolkmer -, conferindo especial enfoque à possibilidade de sua efetivação em escala parcial, por meio de práticas plurais inseridas no âmbito do espaço institucionalizado.

Tendo em vista que a doutrina do pluralismo jurídico democrático-participativo opõe-se à ideia do monopólio, por parte do Estado, de toda a juridicidade, traça-se, na primeira parte, um panorama do monismo jurídico estatal. Nisso, implica delimitar conceitualmente o modelo monista e estudar os ciclos de seu desenvolvimento, desde a origem até o estabelecimento na condição de modelo hegemônico.

No segundo momento, cabe tecer algumas considerações acerca da crise do paradigma jurídico monista. Nesse ponto, se abordam as insuficiências do Poder Judiciário, atualmente; e se problematizam as instabilidades e incoerências da dogmática jurídica e da organização burocrática estatal.

Na terceira parte, deve-se atentar para teoria do pluralismo jurídico. Procede-se, pois, uma breve digressão histórica acerca do surgimento da referida corrente, das diferenças entre o projeto conservador e o projeto emancipatório do pluralismo jurídico, adentrando-se mais especificamente nos aspectos característicos deste último. Por fim, e em atenção ao objetivo do trabalho, analisa-se se podem ser consideradas plurais práticas jurídicas que emergem do bojo da estrutura estatal.

\section{BREVES CONSIDERAÇÕES SOBRE MONISMO JURÍDICO}

Enquanto movimento que nega a figura do Estado como fonte única e exclusiva de juridicidade, o pluralismo jurídico coloca-se em diametral oposição ao monismo jurídico, do que decorre a necessidade de tecer, preliminarmente, algumas considerações a respeito desse modelo e da crise paradigmática que lhe é inerente.

Procedendo a uma leitura embrionária e bastante ampla do monismo, Santos entende-o como a teoria que reputa válida apenas uma ordem jurídica, seja ela a do direito natural, seja a do direito estatal. Isto é, "monismo jurídico significa o reconhecimento de apenas uma ordem jurídica, estatal ou universal" (SANTOS, 2009, p. 57). Para o autor, tal conceito é o que melhor traduz a acepção da palavra, de modo que a identificação do monismo com a atuação estatal não é elemento necessariamente indispensável.

Diferente é a lição de Carvalho (2010, p. 14), para quem o monismo jurídico pode ser compreendido como uma "concepção, consolidada ao longo da modernidade, segundo a qual, o Estado é o centro único do poder e o detentor do monopólio de produção das normas jurídicas". Ademais, pelo modelo monista, segundo Carvalho (2010, p. 14), não só a atividade legislativa é centralizada, como também a de resolução de controvérsias, incumbindo exclusivamente ao Estado o poder/dever de exercer a jurisdição. 
As primeiras referências ao monismo jurídico remontam aos séculos XVII e XVIII, com a filosofia contratualista de John Locke, Thomas Hobbes e Jean-Jacques Rousseau. A ideia de "contrato social" que cada qual dos filósofos lança em suas obras para explicar as origens do Estado, cinge-se, ainda que teórica e remotamente, ao monismo jurídico, à medida que concentra o poder de produzir o ordenamento jurídico dentro dos domínios estatais, suprimindo sistemas normativos alternativos. (MORAIS, 2011, p. 1).

Um retrospecto histórico indica que quando em vias de esgotar-se o feudalismo, registrou-se a passagem do "pluralismo político medieval", cujos contornos eram evidentes na multiplicidade de centros de poder político, sob o comando da nobreza, do clero, de universidades, reinos, estamentos, organizações e corporações de ofício, para um estágio de consolidação do monismo estatal. (WOLKMER, 2001, p. 27).

Reputa-se tal contexto como o primeiro "ciclo" do monismo jurídico e sua mola propulsora teriam sido "os interesses absolutistas da monarquia fortalecida e as novas necessidades de regulamentação centralizadora das práticas mercantis prevalecentes” (WOLKMER, 2001, p. 51), ambos os fatores decorrentes do surgimento do Estado Moderno.

Nesse sentido, Bobbio (2006, p. 27) esclarece que:

Com a formação do Estado moderno, ao contrário, a sociedade assume uma estrutura monista, no sentido de que o Estado concentra em si todos os poderes, em primeiro lugar aquele de criar o direito: não se contenta em concorrer para esta criação, mas quer ser o único a estabelecer o direito, ou diretamente através da lei, ou indiretamente através do reconhecimento e controle das normas de criação consuetudinária. Assiste-se assim [...] ao processo de monopolização da produção jurídica por parte do Estado.

Concluiu o aludido autor, fazendo referência à Ehrlich, que sob a égide do Estado Moderno, requer-se do juiz, quando da resolução das controvérsias, a estrita observância das regras emanadas pelo Estado, restando as demais descartadas. Isso porque o direito natural e o direito positivo não mais figuram em um mesmo patamar, consagrando-se o segundo, pelo fato de ser posto e aprovado pelo Estado, como o "único verdadeiro direito". (BOBBIO, 2006, p. 29).

Do declínio do Estado Absolutista, fenômeno registrado a partir de uma série de eventos históricos de grande importância, como a Revolução Gloriosa, o Iluminismo e a Revolução Francesa, desenha-se o Estado Liberal, forte no combate às ideias absolutistas (MORAIS, 2011, p. 1). Essa nova ordem mundial encampa um segundo ciclo do monismo jurídico.

Agora o direito estatal deixa de representar exclusivamente as aspirações da monarquia absolutista, para tornar-se produto das novas ideias e condições efervescidas com a ascensão do capitalismo e com a crescente produção industrial. A classe social burguesa emergente molda o direito à luz do liberalismo econômico e para que sirva de instrumento à manutenção do poder burguês. (WOLKMER, 2001, 51).

Nesse cenário, privilegia-se mais fortemente a lei escrita como fonte do direito, de modo que "é perceptível a gradativa postulação e redução do Direito Estatal ao Direito Positivo; consagrando-se a exegese de que todo o Direito não só é Direito enquanto produção do Estado, mas, sobretudo, de que somente o Direito Positivo é verdadeiramente Direito." (WOLKMER, 2001, p. 55).

O terceiro ciclo do monismo jurídico deslinda-se das contribuições colacionadas pelo formalismo dogmático da Escola de Viena, cujo expoente principal é a 'teoria pura do Direito', de Hans Kelsen. 
Pela proposta de Kelsen, o caráter monista do direito decorre da sua existência somente na forma de um sistema único emanado do Estado. Não haveria espaço para dualismo, Estado e Direito encontrar-se-iam fundidos em um só instituto. (ANTUNES, 2008, p. 27).

Assim também entende Wolkmer (2000, p. 76), ao analisar a obra de Kelsen:

\begin{abstract}
A concepção monista, embasada no extremismo lógico e formalista da dogmática normativista tende a eliminar o dualismo jurídico-estatal, na perspectiva de que o Estado é identificado com a ordem jurídica, ou seja, o Estado encarna o próprio direito em determinado nível de ordenação, constituindo um todo único. [...] O Estado legitima o seu poder pela segurança e pela validade oferecida pelo Direito, que, por sua vez, adquire força no respaldo proporcionado pelo Estado.
\end{abstract}

A Teoria Kelseniana, com o afã de depurar a ciência do Direito, repele o conteúdo social da regra jurídica, tampouco reconhece a existência de um Direito supralegal. Debruça-se sobre a questão da validade da norma, afastando-se das investigações acerca de sua justiça, de modo que "todo conhecimento possível só comprova seu rigor formal e sua aridez técnica". (WOLKMER, 2000, p. 161). Assim, a formulação de Kelsen, como a de outros teóricos igualmente identificados com o positivismo jurídico, encara o formalismo como um de seus principais elementos.

Sem o condão de adentrar nos meandros do formalismo jurídico, cabe tecer algumas considerações a respeito do tema.

Largamente vinculado ao normativismo Kelseniano, o formalismo jurídico, compreendido como a visão meramente formal que se dá a justiça, é caracterizado por uma extrema rigidez processual e pela proximidade com a dogmática jurídica, a qual toma a norma como único elemento de estudo do direito. (ANTUNES, 2008, p. 29).

Alusivo ao assunto pontua Bobbio (2006, p. 131)

[...] o termo 'direito' é então absolutamente avalorativo, isto é, privado de qualquer conotação valorativa ou ressonância emotiva: o direito é tal que prescinde o fato de ser bom ou mau, de ser um valor ou um desvalor. Deste comportamento deriva uma particular teoria da validade do direito, dita teoria do formalismo jurídico, na qual a validade do direito se funda em critérios que concernem unicamente à sua estrutura formal (vale dizer, em palavras simples, o seu aspecto exterior), prescindindo do seu conteúdo.

Não obstante, conforme alertado por Antunes (2008, p. 31), apesar da pretensa segurança jurídica que exibem, modelos assentados no rigor formal estão propensos, em algum momento de seu desenvolvimento, a não corresponderem às exigências e práticas sociais, em virtude de seu caráter estanque e rígido.

Nesse sentido, engendrou-se, a partir dos anos 1970 e 1980, o quarto e último grande ciclo do monismo jurídico. As novas demandas político-econômicas, o aumento dos conflitos entre grupos e classes sociais e o aparecimento de um sem número de contradições materiais e culturais, típicas das sociedades contemporâneas de massa, colocam, nesta fase, o direito estatal em constante ultrapassamento. (WOLKMER, 2001, p. 58).

Por assim dizer, a quarta etapa desvela o esfacelamento do paradigma jurídico positivistacentralizador, construído e sustentado por mais de três séculos. Todavia, em que pese o cenário de rupturas, o Estado, por sua vez, vale-se da dogmática jurídica e de uma estrutura altamente institucionalizada, para manter-se hegemônico. (WOLKMER, 2001, p. 59).

Tal descompasso entre as "estruturas socioeconômicas e as instituições jurídico-políticas”, emprestando a expressão de Faria (1988, p. 18), coloca em voga a inevitável questão da crise do aludido modelo de legalidade, tema que será objeto do próximo tópico. 


\title{
2 A CRISE DO PARADIGMA JURÍDICO MONISTA
}

Pelo até aqui exposto, constata-se que há muito a cultura jurídica predominante, pelo menos nos países ocidentais, leva a marca do unitarismo. A larga maioria dos Estados limitou-se a reproduzir idealizações normativas características de "determinada legalidade estatal e racionalização formal”, pertencentes a um modo particular de produção econômico-social, qual seja, o capitalista. (WOLKMER, 2001, p. 66).

Conquanto, a partir da última metade do século $\mathrm{XX}$, as sociedades situadas no centro e, especialmente, na periferia capitalista, passaram a travar contato com "novas e flexíveis modalidades de produção do capital, radicais contradições sociais e instabilidades continuadas que refletiram crises, tanto em nível de legitimidade, quanto de produção e aplicação da justiça”. (WOLKMER, 2001, p. 70).

Outrossim, segundo Faria, mostrou-se axiomática

\begin{abstract}
a desarticulação estrutural das legislações vigentes com forte inspiração liberal, de modo que a ideia de crise traduz o risco de rompimento da racionalidade jurídica burguesa - ou seja, a possibilidade de não mais se acreditar na objetividade da lei, na decantada neutralidade do legislador e na pretensa completude dos ordenamentos. A noção de 'crise', nesta perspectiva, é assim apresentada como um momento de irracionalidade política, gerando o caos econômico e a desordem social, exigindo sua urgente superação para o reestabelecimento da racionalidade anterior ou para o estabelecimento de uma nova racionalidade. (FARIA, 1988, p. 20).
\end{abstract}

Há quem considere, a exemplo de Streck (2006, p. 1) e Wolkmer (2001, p. 70), que a referida crise, por seus tão estruturais contornos, é de cunho paradigmático.

A título de esclarecimento, entende-se, por paradigma, o conjunto de crenças fundamentais dotada de unidade e aceitação pela comunidade científica. Em direito, o campo da Dogmática Jurídica é compreendido como um autêntico paradigma científico, no sentir de Wolkmer (2001, p. 69). Porquanto, na medida em que a Dogmática Jurídica ocupa-se unicamente do estudo das normas abstratas, postas pelo Estado, dá as costas para uma gama de problemas contemporâneos suscitados na realidade fática, desencadeando o aludido cenário de crise.

Entende Wolkmer (2001) que a Dogmática Jurídica,

[...] por elaborar sua construção sistemática sobre um direito identificado com a lei e produzido unicamente pelos órgãos estatais, minimiza, na tradição de suas fontes formais, as múltiplas manifestações de exteriorização normativa (direito espontâneo, informal, extra-estatal etc.), representadas pelos corpos sociais autônomos (sindicatos, assembleias, corporações, comunas, associações profissionais, grupos sociais de toda espécie etc.). (WOLKMER, 2001, p. 69).

De mais a mais, no contexto da dogmática jurídica, os fenômenos sociais que chegam ao Judiciário
passam a ser analisados como meras abstrações jurídicas, e as pessoas, protagonistas
do processo são transformadas em 'autor' e 'réu', 'reclamante' e 'reclamado'. [...]
Isso significa dizer, que os conflitos sociais não entram nos fóruns e nos tribunais
graças as barreiras criadas pela dogmática jurídica. (STRECK, 2007, p. 32).

Aproveitando o ensejo, uma vez que o excerto da obra de Streck faz referência à atuação jurisdicional, vale destacar que a crise da Dogmática Jurídica é também uma crise do Estado e, por conseguinte, do Poder Judiciário. Nesse âmbito, a crise desencadeou-se, entre outros fatores, pelo crescimento e a complexidade de conflitos sociais aliados à falta de estrutura física, tecnológica e financeira do Estado, o rebuscamento da linguagem jurídica, o acúmulo de processos, etc. (GHISLENI; SPLENGER, 2011, p. 24). 
Por seu lado e concernente ao assunto, Wolkmer (2001, p. 100) considera que o descompromisso e falta de criatividade do Poder Judiciário, no enfrentamento dos graves problemas de ordem política e social, é histórico. Em sua visão, trata-se o Judiciário de um "órgão elitista" que, sob a falsa alcunha de neutralidade no atuar, encobre a condição de submissão aos ditames da ordem dominante, além de lançar mão de mecanismos burocráticos procedimentais onerosos, que, por si só, constituem uma barreira ao acesso dos menos providos de recursos.

Há que se registrar, que a burocracia, conforme supracitado, é forma de organização utilizada não apenas no Poder Judiciário, mas em todas as instituições estatais, e revela, também, uma das faces da crise do monismo jurídico.

A origem do fenômeno burocrático, na asserção de Wolkmer (2000, p. 44), encontra-se na formação dos grandes impérios e na sedimentação do conceito de Estado. Contudo, foi a partir do século XX que a burocracia atingiu o seu apogeu, enquanto instrumento a serviço do modelo capitalista de produção, por comportar a eliminação das relações pessoais e vincular todas as atividades ao fim pretendido pelo sistema. (LEFORT, 1979, p. 156).

Empreendendo uma crítica à burocracia, Wolkmer (2000, p. 63) assevera que:

\begin{abstract}
A burocracia se alicerça numa dimensão alienadora, mecanicista e desumanizadora, não se coadunando com as consubstanciais necessidades e exigências do indivíduo. A pseudo-eficácia dos procedimentos tecnoburocráticos fragmenta e obscurece o potencial criativo do homem, assumindo, cada vez mais, proporções profundas e persistentes, adonando-se de áreas que jamais se poderiam imaginar.
\end{abstract}

Nesse sentido, conclui o autor, que já é tempo de a "administração política da vida pública" abandonar o modelo burocrático, que tende apenas a subordinar os indivíduos, em favor de meios de organização mais democráticos, plurais e participativos. (WOLKMER, 2000, p. 63).

Por outro lado, a crise que se apresenta revela certo aspecto bastante particular: a disfuncionalidade do Estado ao deparar-se com novos e contraditórios problemas, especialmente, os conflitos de cunho coletivo próprios do final do século XX. Isso porque, o modelo monista, em sua unicidade, estatalidade, positivação e racionalidade, foi historicamente montado para administrar conflitos de natureza individual e civil e, diante das demandas coletivas, afigura-se incapaz de apreciá-las. (WOLKMER, 2001, p. 97).

Em consonância, Streck (2006, p. 258), para quem a crise é do modelo de direito, modelo esse que, em tese, estaria "preparado para o enfrentamento de conflitos interindividuais", mas desprovido de "condições de enfrentar/atender às demandas de uma sociedade repleta de conflitos supraindividuais".

Portanto, a complexidade da conjuntura pós-moderna faz cair por terra a concepção de que o pluralismo social é passível de caber em uma unidade formal. Mostra-se emergente, porque, pensar em modelos alternativos de direito.

\title{
3 Pluralismo jurídico: POSSibiliddade de CONCRETizaÇÃo EM ESCALA PARCIAL
}

A vertente teórica denominada de pluralismo jurídico, para além de seu viés propositivo acerca da formação de uma nova cultura no Direito, assenta-se enquanto teoria jurídica crítica do paradigma positivista. Dessa feita, tem como pressuposto elementar problematizar acerca da hegemonia estatal, na produção, aplicação e fiscalização do Direito. (ANTUNES, 2008, p. 18).

Antunes indica alguns caracteres que devem integrar uma teoria que se pretende crítica: 
-busca uma reflexão interdisciplinar na análise do direito,

-efetua uma relação entre o poder e o saber e visa desconstruir discursos que desconsiderem os conflitos subjacentes a suposta organização harmônica propiciada pelo direito,

-não prescinde da política como fenômeno relacionado à juridicidade e que condiciona sua manifestação e aplicação,

-postula um caráter emancipatório para o direito, visando a concretização de uma sociedade autônoma,

-dirige-se também contra a produção do saber jurídico denunciando, sobretudo, a reprodução do dogmatismo no ensino jurídico, que se afasta da reflexão crítica acerca do direito. (ANTUNES, 2008, p. 18).

Entendendo que o pluralismo jurídico contempla os supracitados elementos, passa-se a uma breve digressão histórica acerca de sua origem. Vale esclarecer, a priori, que, tal contextualização, atine ao campo teórico, isso porque, como bem nos lembram Albernaz e Wolkmer (2008, p. 2), o pluralismo jurídico, antes de constituir-se enquanto formulação científica, é uma situação de fato, cujo surgimento não se deu em um momento específico, mas revela-se paulatinamente "na historicidade existencial de cada unidade coletiva concreta em seu empreendimento de configurar uma expressão de juridicidade que acomode suas sociabilidades, anseios ou interesses".

Com efeito, sob uma abordagem teórica, o pluralismo jurídico encontra em Eugen Erlihch um de seus precursores. Corifeu da Escola do Direito Livre, Erlihch propalava, e vivenciava haja vista as inúmeras pesquisas de campo que realizou -, a relevância da sociologia do direito, uma vez que, para ele, a sociedade constituir-se-ia em terreno de estudo deveras mais fértil para os juristas do que a norma, em toda sua abstração. Não por acaso, após a publicação do trabalho que lançava esse pensamento de vanguarda, Erlihch fora rebatido pelo seu ex-aluno, Hans Kelsen, com a afamada Teoria Pura do Direito. (ANTUNES, 2008, p. 31).

Pode-se afirmar que as formulações de Erlihch conectam-se ao pluralismo, ainda que embrionariamente, devido a defesa por ele empreendida de um direito livre das amarras do legalismo excessivo, e, principalmente, pelas investigações científicas que procedera acerca das práticas normativas informais, nas mais diversas organizações e associações da sociedade, a exemplo da empreendida nas comunidades de camponeses quando da realização dos "Seminários do Direito Vivo". (ANTUNES, 2008, p. 34).

Por isso, e em arremate, "a relevância das questões suscitadas pela escola do direito livre para o pluralismo jurídico decorre da antecipação da crítica à pretensão estatal de deter a fonte exclusiva de juridicidade e produção normativa”. (ANTUNES, 2008, p. 33.).

Dentre as inúmeras impressões que os teóricos atribuíram ao pluralismo jurídico ao longo de mais de um século, cabe destacar o contraste entre o projeto conservador e o projeto emancipatório de pluralismo jurídico, aspecto bastante explorado por Wolkmer na obra "Pluralismo Jurídico: Fundamentos para uma nova cultura do direito".

Em comentário sobre o projeto conservador, Albernaz e Wolkmer (2008, p. 2) o consideram uma representação dos ideais neoliberais, "cuja ênfase se dá sobre processos como a desregulamentação estatal, a globalização e a acumulação flexível de capital, a formação de blocos econômicos, as políticas de privatização, a flexibilização do trabalho" etc. Esse projeto, em razão de valorizar a individualidade, acaba por enfraquecer a força política das massas, e desposá-las de uma participação ativa e democrática nos assuntos do Estado. 
Por outro lado, o projeto emancipatório, na linha defendida por Wolkmer, ampara-se, filosoficamente, na compreensão sobre a complexidade da vida humana, considerando a diversidade de valores, aspirações e interesses que a circundam. Porquanto, sugere a edificação de um pluralismo jurídico sob as bases das "práticas sociais insurgentes e autônomas, motivadas pela satisfação das necessidades humanas essenciais, e em uma reordenação, desconcentração e descentralização do espaço público, no sentido de multiplicar o seu locus e ampliar seu cunho democrático." (ALBERNAZ; WOLKMER, 2008, p. 3).

Sintetiza Wolkmer (2001):

\begin{abstract}
As transformações da vida social constituem, assim, a formação primária de um ‘jurídico' que não se fecha exclusivamente em proposições genéricas em regras estáticas e fixas formuladas para o controle e a solução dos conflitos, mas se manifesta como resultado do interesse e das necessidades de agrupamentos associativos e comunitários, assumindo um caráter espontâneo, dinâmico, flexível e circunstancial. (WOLKMER, 2001, p. 152).
\end{abstract}

Diante da inconcebível ideia de que o Direito Estatal positivado está apto a suprir as inúmeras expectativas que envolvem a vida social, a corrente pluralista dita comunitário-participativa, propõe extrair normatividade de canais diferentes dos habitualmente consagrados. Daí a reconhecer em atores coletivos, como grupos organizados autônomos ou semiautônomos, verdadeiras instâncias de produção normativa. (WOLKMER, 2001, 151).

Segundo Wolkmer (2001), o pluralismo jurídico comunitário-participativo tem sua natureza e especificidade determinadas por certos princípios valorativos, quais sejam: a) autonomia, entendida como a independência em relação ao poder governamental; b) descentralização, com a distribuição do poder entre esferas locais; c) participação, decorrente da descentralização, à medida que a fragmentação do poder exige atuação ativa, desde a base; d) localismo, que atribui ao poder local o nível mais descentralizado do poder estatal; e) diversidade, admitindo-se as diferenças existentes no mundo da vida; f) tolerância, enquanto pressuposto para o exercício da liberdade e autodeterminação humanas.

Na análise de Antunes (2008, p. 62), o modelo de pluralismo jurídico comunitário-participativo, formulado por Wolkmer, fundamenta-se em duas frentes. Uma de efetividade material, que compreende a "emergência de novos sujeitos coletivos" e a "satisfação de necessidades humanas fundamentais". Outra de efetividade formal, que impõe à "reordenação do espaço público mediante uma política democrático-comunitária descentralizadora e participativa", o "desenvolvimento da ética concreta da alteridade" e a "construção de processos para uma racionalidade emancipatória".

Desse modo, percebe-se o esforço do autor em relação ao conteúdo e aos atores presentes nessa nova modalidade de conceber o direito, como também na prospecção de mecanismos para implementá-lo.

Quando refere a novos sujeitos coletivos, Wolkmer (2001) os compreende como:

[...] identidades coletivas conscientes, mais ou menos autônomas, advindos de diversos estratos sociais, com capacidade de auto-organização e autodeterminação, interligadas por formas de vida com interesses e valores comuns, compartilhando conflitos e lutas cotidianas que expressam privações e necessidades por direitos, legitimando-se como força transformadora do poder e instituidora de uma sociedade democrática, descentralizadora e igualitária. (WOLKMER, 2001, p. 240).

Nesse âmbito, destaca-se o protagonismo assumido pelos movimentos sociais. Dada a sua postura reivindicatória incisiva, tais grupos possuem grande potencialidade de ver materializados os direitos de sua pauta. Além disso, atuam de modo a estimular "a convivência da divergência", 
fortalecendo um dos valores elementares do modelo pluralista: a ética da alteridade. (ANTUNES, 2008, p. 115).

Não obstante, em que pese a recorrente identificação dos novos sujeitos coletivos com grupos organizados à margem da juridicidade estatal e independes dela, Albernaz e Wolkmer (2008, p. 68) ressaltam a existência de um pluralismo jurídico controlado, no qual as manifestações plurais, sejam elas legislativas ou jurisdicionais, são absorvidas e regulamentadas pelo Estado. Igualmente, a partir de uma aproximação do pluralismo jurídico com a questão da administração da justiça, a fim de inserir elementos daquele, como a participação e a descentralização, no âmbito desta, verifica-se que os referidos elementos podem advir tanto do interior quanto do exterior da legalidade oficial estatal. Assim,

\begin{abstract}
o modelo que propõe novas manifestações e formas de juridicidade traduz uma modalidade de administração da justiça em que atores, como os movimentos sociais, e os próprios componentes oficiais do sistema jurídico adquirem uma nova dimensão no processo de reivindicação e aplicação de direitos, na qual os sujeitos participam do processo decisório e da gestão da administração da justiça. (ANTUNES, 2008, p. 117). (grifos nossos).
\end{abstract}

Wolkmer $(2001,289)$ transita por linha de pensamento parecida ao distinguir duas estratégias essenciais à efetivação do pluralismo jurídico. Para o autor, se em longo prazo o pluralismo se efetiva pela insurgência de práticas legais não-institucionalizadas produzidas fora da órbita do direito positivo estatal - o que representa uma brusca ruptura de paradigmas, é de se admitir, no curto ou médio prazo, manifestações pluralistas escavadas de dentro da própria ordem legal estatal.

Nesse segundo contexto, a utilização de procedimentos de baixo nível de institucionalização pode ocorrer em nível da produção normativa, a exemplo das convenções coletivas do trabalho e ações propostas por sujeitos coletivos, ou na esfera da resolução de conflitos, com a adesão a procedimentos dotados de maior informalidade e voltados ao consenso, como a arbitragem, a conciliação, a mediação e os juizados especiais. (WOLKMER, 2001, 292).

No mesmo sentido, é a lição de Trentin (2011, p. 64):

[...] O Estado preocupou-se com a implementação dos Juizados Especiais, editou a lei da Ação Civil Pública, facilitou o desenvolvimento de programas que promovessem a mediação e a conciliação, promulgou a lei da arbitragem, enfim, consagrou os novos direitos e as novas formas de se fazer direito, através dos equivalentes jurisdicionais. Não fora de tempo, pois antes das ações acima, o Estado controlou, por muito tempo, a criação da legislação e a resolução dos conflitos, de forma a monopolizar tal poder. A esse fenômeno [...] foi dado o nome de monismo jurídico, que nada mais é do que um paradigma ultrapassado de sistema de jurisdição.

Portanto, verifica-se que conceber o pluralismo jurídico como outro paradigma para o Direito não implica em adotar uma postura "anti-Estado", uma vez que, em escala parcial de sua concretização, práticas plurais podem emergir de dentro da estrutura estatal. O objetivo do pluralismo jurídico não é desprezar o direito estatal, mas, sim, reconhecer nele a condição de apenas uma das muitas formas jurídicas que podem existir na sociedade.

\title{
Conclusão
}

O presente artigo dedicou-se ao estudo do pluralismo jurídico, buscando averiguar a possibilidade de sua concretização a partir de práticas inseridas no bojo da estrutura estatal. Para tanto, elegeu-se como marco teórico principal da pesquisa as contribuições de Antonio Carlos Wolkmer acerca do pluralismo jurídico democrático-participativo. 
Preliminarmente, compreendendo que o pluralismo jurídico, enquanto corrente crítica, contesta a hegemonia estatal na produção e a aplicação do Direito, procurou-se abordar a corrente que a ele se opõe, qual seja, a do monismo jurídico estatal. Porquanto, constatou-se que desde a sua origem, em boa medida alinhada ao surgimento do Estado Moderno, o monismo jurídico atravessou alguns ciclos. Destas etapas, a que hoje se encontra em curso, representa o momento de crise do modelo, embora tal situação tente ser encoberta pela dogmática jurídica a todo custo.

Por isso, na segunda parte do estudo, reconhecendo as fragilidades do paradigma monista em atender as demandas de uma sociedade em premente modificação, explorou-se a questão da crise do aludido modelo. Nesse ponto, transitou-se, especialmente, pela disfuncionalidade do Poder Judiciário, bem como pelos percalços do padrão de organização estatal burocrático.

Por sua vez, a etapa derradeira do artigo perquiriu o pluralismo jurídico. Inicialmente, definiu-se como marco para abordagem o projeto emancipatório do pluralismo, posto que paralelo a ele existe um projeto conservador, servil aos ideais do capital. Feito isso, identificou-se os aspectos centrais da teoria pluralista e atinente à sua efetivação, constatou-se a possiblidade de sua ocorrência tanto a partir de manifestações advindas da margem da legalidade institucionalizada, pelo protagonismo de novos atores, quanto de práticas reconhecidas e incorporadas pelo próprio Estado, que, em que pese não provoquem rupturas bruscas, podem, em nível parcial, concretizar o pluralismo jurídico.

\section{REFERÊNCIAS}

ANTUNES, Fernando Luís Coelho. O pluralismo jurídico: marco teórico para a discussão do acesso à justiça. Dissertação (Mestrado em Direito). Centro de Ciências Jurídicas. UFSC, Florianópolis, 2008.

BOBBIO, Norberto. O Positivismo Jurídico: Lições de Filosofia do Direito. São Paulo: Ícone, 2006.

CARVALHO, Lucas Borges de. Caminhos (e descaminhos) do pluralismo jurídico no Brasil. In: Pluralismo Jurídico: os novos caminhos da contemporaneidade. Org. WOLKMER, Antonio Carlos; NETO, Francisco Q. Veras; LIXA, Ivone M. São Paulo: Saraiva, 2010.

FARIA, José Eduardo. Eficácia Jurídica e violência simbólica. São Paulo: EDUSP, 1988.

GHISLENI, Ana Carolina; SPENGLER, Fabiana Marion. Mediação de conflitos a partir do Direito Fraterno. Santa Cruz do Sul: Edunisc, 2011.

LEFORT, Claude. O que é burocracia. Política \& Sociedade. São Paulo: Nacional, 1979. Disponível em: <http://www.forumjustica.com.br/wp-content/uploads/2015/08/LEFORT-Claude--lements-dune-critique-de-la-bureaucratie.-Genebra---ditions-Droz-pp.-52-86.pdf >. Acesso em: 12 jul. 2017.

MORAIS, Márcio Eduardo da Silva Pedrosa. Sobre a evolução do Estado. Do Estado absolutista ao Estado Democrático de Direito. Jus Navigandi, ISSN 1518-4862, Teresina, ano 16, n. 2833, 4 abr. 2011. Disponível em: <https://jus.com.br/artigos/18831/sobre-a-evolucao-do-estado>. Acesso em: 11 jul. 2017.

SANTOS, Ronaldo Lima dos. Teoria das normas coletivas. 2. ed. São Paulo: LTr, 2009. 
STRECK, Lenio Luiz. A atualidade do debate da crise paradigmática do direito e a resistência positivista ao neoconstitucionalismo. Revista do Instituto de Pesquisas e Estudos, 2006. Disponível em: < https://jus.com.br/artigos/18831/sobre-a-evolucao-do-estado. Acesso em: 12 jul. 2017.

STRECK, Lenio Luiz. Hermenêutica e Ensino Jurídico em Terrae Brasilis. Revista da Faculdade de Direito UFPR, Curitiba, PR, Brasil, dez. 2007. ISSN 2236-7284. Disponível em: <http://revistas.ufpr.br/direito/article/view/13495>. Acesso em: 21 jul. 2017. doi:http:// dx.doi.org/10.5380/rfdufpr.v46i0.13495.

WOLKMER, Antonio Carlos. Ideologia, Estado e Direito. 3. ed. ver. ampl. São Paulo: Editora Revista dos Tribunais, 2000.

. Pluralismo Jurídico: Fundamentos de uma nova cultura no Direito. 3 ed. rev. e atual. São Paulo: Alfa Ômega, 2001.

; ALBERNAZ, Renata Ovenhausen. As questões delimitativas do direito no Pluralismo Jurídico. Sequência: Estudos Jurídicos e Políticos, Florianópolis, p. 67-94, set. 2010. ISSN 2177-7055. Disponível em: <https://periodicos.ufsc.br/index.php/sequencia/article/view/ 21777055.2008v29n57p67>. Acesso em: 22 jul. 2017. doi:http://dx.doi.org/10.5007/21777055.2008v29n57p67.

Recebido em: 14 ago. 2017.

Aceito em: 26 out. 2017. 